\title{
ANALISIS METODE ELECTRE PADA PEMILIHAN USAHA KECIL HOME INDUSTRY YANG TEPAT BAGI MAHASISWA
}

\author{
${ }^{1}$ Sinta Maulina Dewi, ${ }^{2}$ Agus Perdana Windarto \\ ${ }^{12}$ STIKOM Tunas Bangsa \\ Jln. Jenderal Sudirman Blok A No.1/2/3, Pematangsiantar \\ Email:sintamaulinadewi033@gmail.com, agus.perdana@amiktunasbangsa.ac.id
}

(Diterima: 2 Mei 2019, direvisi: 21 Juni 2019, disetujui: 28 Agustus 2019)

\begin{abstract}
ABSTRAK
Home industry saat ini menjadi cabang usaha yang banyak digemari oleh masyarakat, karna sifatnya yang tidak membutuhkan modal yang sangat besar. Home industry juga bisa menjadi penyaluran kreatifitas bagi Mahasiswa yang kreatif, dan juga mandiri. Penelitian ini bertujuan agar dapat memilih usaha kecil Home industry yang tepat bagi mahasiswa menggunakan metode electre. Metode pengumpulan data dilakukan dengan wawancara dan angket atas 350 sampel Mahasiswa STIKOM Tunas Bangsa yang ingin membuka usaha kecil. Berdasarkan hasil tersebut diperoleh Kriteria yang digunakan dalam pemilihan usaha kecil yang cocok bagi mahasiswa ialah Modal (X1), Keuntungan (X2), Bahan Baku (X3), dan Market (X4). Dalam penelitian ini terdapat tiga alternatif yaitu, $\left(\mathrm{A}_{1}\right)$ Olahan Kripik, $\left(\mathrm{A}_{2}\right)$ Olahan Kue Basah, dan $\left(\mathrm{A}_{3}\right)$ Olahan Gorengan. Hasil penelitian menyimpulkan bahwa Keripik $\left(\mathrm{A}_{1}\right)$ menjadi Home industry yang tepat bagi mahasiswa. Diharapkan hasil dari penelitian ini dapat memberikan pemahaman kepada mahasiswa yang ingin membuka usaha kecil.
\end{abstract}

Keywords: Sistem Pendukung Keputusan, Metode ELECTRE, Home industry, Mahasiswa.

\section{PENDAHULUAN}

Home industry atau usaha dirumah adalah tempat tinggal yang merangkap tempat usaha, baik itu berupa usaha jasa, kantor, hingga perdagangan dan semua jenis kegiatan ekonominya dipusatkan di rumah [1]. Usaha yaitu suatu kegiatan yang dilakukan dan dikembangkan oleh seseorang atau kelompok dengan tujuan menghasilkan berbagai jenis barang dan jasa yang dibutuhkan oleh masyarakat dalam kehidupannya [2]. Home industry saat ini menjadi cabang usaha yang banyak digemari oleh masyarakat, karna sifatnya yang tidak membutuhkan modal yang sangat besar. Home industry juga bisa menjadi penyaluran kreatifitas bagi Mahasiswa yang kreatif, dan juga mandiri. Salah satu Home industry yang patut dikembangkan ialah dibidang kuliner, karena pada bidang ini, masyarakat menjadi lebih kreatif dikarenakan begitu banyaknya persaingan dan inovasi-inovasi baru yang dapat dikembangkan. Usaha ini pun menjadi sasaran utama bagi mahasiswa yang mencintai bidang ini. Namun, tidak jarang juga sebagian mahasiswa yang tidak dapat menentukan usaha apa yang akan diolahnya. Pada penelitian ini, akan membantu dalam memilih usaha kecil home industry yang tepat bagi mahasiswa.

Banyak cabang ilmu komputer yang dapat menyelesaikan permasalah yang sifatnya kompleks baik prediksi, estimasi, perangkingan, klasifikasi, asosiasi dan lain-lain. Cabang ilmu komputer tersebut adalah Artificial Intelligence seperti datamining [3],[4],[5], sistem pendukung keputusan (SPK) [6][13], sistem pakar[14],[15], jaringan saraf tiruan[16]-[19], logika fuzzy [20],[21], datamining [22]-[27] dan lain-lain. Berdasarkan permasalahan tersebut maka peneliti menggunakan Sistem Pendukung Keputusan dengan metode ELECTRE. ELECTRE salah satu metode pengambilan keputusan multikriteria berdasarkan pada konsep Outrangking dengan menggunakan perbandingan berpasangan dari alternatif-alternatif berdasarkan setiap kriteria yang sesuai[28],[29]. Penelitian tersebut pernah dilakukan pada penelitian sebelumnya [30],[31]. Penelitian ini menggunakan pendekatan fuzzy logic pada pemilihan Home industry yang tepat bagi mahasiswa. Penggunaan Metode ELECTRE memiliki beberapa kelebihan yakni keputusan multikriteria berdasarkan pada konsep Outranking dengan menggunakan perbandingan berpasangan dari alternatif-alternatif berdasarkan setiap kriteria yang sesuai [28] sehingga sesuai dengan kasus-kasus dengan banyak alternatif namun hanya sedikit kriteria yang dilibatkan. Tujuan dari penelitian ini adalah untuk menganalisa dan menguji keakuratan metode ELECTRE dalam pemilihan usaha kecil Home industry yang tepat. 


\section{TINJAUAN PUSTAKA}

\subsection{Home industry}

Merupakan usaha dirumah adalah tempat tinggal yang merangkap tempat usaha, baik itu berupa usaha jasa, kantor, hingga perdagangan dan semua jenis kegiatan ekonominya dipusatkan di rumah[1]Usaha yaitu suatu kegiatan yang dilakukan dan dikembangkan oleh seseorang atau kelompok dengan tujuan menghasilkan berbagai jenis barang dan jasa yang dibutuhkan oleh masyarakat dalam kehidupannya [2].

\subsection{Elimination Et Choix Traduisant Ia Realite}

ELECTRE salah satu metode pengambilan keputusan multikriteria berdasarkan pada konsep Outrangking dengan menggunakan perbandingan berpasangan dari alternatif-alternatif berdasarkan setiap kriteria yang sesuai[28],[29]. Penelitian tersebut pernah dilakukan pada penelitian sebelumnya [30],[31]. Penelitian ini menggunakan pendekatan fuzzy logic pada pemilihan Home industry yang tepat bagi mahasiswa. Perbedaan dengan penelitian yang sedang dilakukan adalah hasil akhir berupa rangking pemilihan Home industry dan metode yang digunakan.

\section{METODE PENELITIAN}

Penelitian ini dilakukan di STIKOM Tunas Bangsa Pematangsiantar. Penelitian melakukan pengumpulan data dengan cara wawancara dan memberikan angket kepada 250 sampel mahasiswa yang ingin membuka usaha Home Indutri. Adapun Kriteria yang digunakan dalam pemilihan usaha kecil yang cocok bagi mahasiswa ialah Modal (X1), Keuntungan (X2), Bahan Baku (X3), dan Market (X4). Dalam penelitian ini terdapat tiga alternatif yaitu, $\left(\mathrm{A}_{1}\right)$ Olahan Kripik, $\left(\mathrm{A}_{2}\right)$ Olahan Kue Basah, dan $\left(\mathrm{A}_{3}\right)$ Olahan Gorengan.

Langkah-langkah metode ELECTRE adalah sebagai berikut:

\subsection{Normalisasi matriks keputusan}

Dalam prosedur ini, setiap atribut diubah menjadi nilai yang comparable. Setiap normalisasi dari nilai $\mathrm{x}_{\mathrm{ij}}$ dapat dilakukan dengan rumus:

$$
r_{11}=\frac{x_{11}}{\sqrt{\sum_{i=1}^{m} x^{2}{ }_{i j}}}
$$

untuk $\mathrm{i}=1,2,3 \ldots, \mathrm{m}$ dan $\mathrm{j}=1,2,3, \ldots, \mathrm{n}$.

Sehingga didapat matriks $R$ hasil normalisasi,

$$
R=\left[\begin{array}{cccc}
r_{11} & r_{12} & \ldots & r_{1 n} \\
r_{21} & r_{22} & \ldots & r_{2 n} \\
\vdots & & & \\
r_{m 1} & r_{m 2} & \ldots & r_{m n}
\end{array}\right]
$$

$\mathrm{R}$ adalah matriks yang telah dinormalisasi, dimana m menyatakan alternatif, $\mathrm{n}$ menyatakan kriteria dan rij adalah normalisasi pengukuran pilihan dari alternatif ke-i dalam hubungannya dengan kriteria ke-j.

\subsection{Pembobotan pada matrik yang telah dinormalisasi}

Setelah di normalisasi, setiap kolom dari matrik $R$ dikalikan dengan bobot-bobot ( $w j)$ yang ditentukan oleh pembuat keputusan. Sehingga, weighted normalized matrix adalah:

$$
\mathrm{V}=\mathrm{RW}=\left[\begin{array}{cccc}
v_{11} & v_{12} & \ldots & v_{1 n} \\
v_{21} & v_{22} & \ldots & v_{2 n} \\
\vdots & v_{m 2} & \ldots & v_{m n}
\end{array}\right]
$$




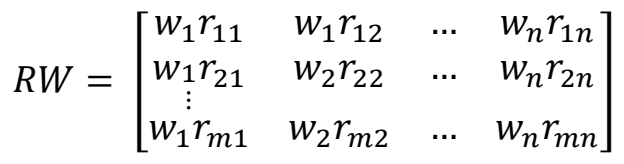

Dimana W adalah

$$
W=\left[\begin{array}{cccc}
w_{1} & 0 & \ldots & 0 \\
v_{21} & w_{2} & \ldots & 0 \\
\vdots & & & \\
0 & 0 & \ldots & w_{n}
\end{array}\right]
$$

\subsection{Menentukan concordance dan discordance index.}

Untuk setiap pasang dari alternatif $\mathrm{k}$ dan $\mathrm{l}(\mathrm{k}, \mathrm{l}=1,2,3, \ldots, \mathrm{m}$ dan $\mathrm{k} \neq 1)$ kumpulan kriteria $\mathrm{J}$ dibagi menjadi dua subsets, yaitu concordance dan discordance. Bilamana sebuah kriteria dalam suatu alternatif termasuk concordance adalah :

$C_{k l}=\{\mathrm{j}, \mathrm{ykj} \geq \mathrm{ylj}\}$, untuk $\mathrm{j}=1,2,3, \ldots, \mathrm{n}$.

Sehingga matrik concordance yang dihasilkan adalah :

$$
C=\left[\begin{array}{ccccc}
- & c_{12} & c_{13} & \ldots & c_{1 n} \\
c_{21} & - & c_{23} & \ldots & c_{2 n} \\
\vdots & c_{m 2} & c_{m 3} & \ldots & - \\
c_{m 1} & c_{m}
\end{array}\right]
$$

Sebaliknya, komplementer dari subset ini adalah discordance, yaitu bila :

$D_{k l}=\{j, y k j<y l j\}, u n t u k j=1,2,3, \ldots, n$.

$D=\left[\begin{array}{ccccc}- & d_{12} & d_{13} & \ldots & d_{1 m} \\ d_{21} & - & d_{23} & \ldots & c_{2 m} \\ \vdots & & & & - \\ d_{m 1} & d_{m 2} & d_{m 3} & \ldots & -\end{array}\right]$

Hitung matriks concordance dan discordance

a. Menghitung matriks concordane

Untuk menentukan nilai dari elemen-elemen pada matriks concordance adalah dengan menjumlahkan bobot-bobot yang termasuk pada himpunan concordance,secara matematis:

$$
C_{k l} \sum_{j \in C_{k l}} w_{j}
$$

b. Menghitung matriks discordance

Untuk menentukan nilai dari elemen-elemen pada matriks discordance adalah dengan membagi maksimum selisih nilai kriteria yang termasuk dalam subset discordance dengan maksimum selisih nilai seluruh kriteria yang ada, secara matematisnya:

$d_{k l}=\frac{\max \left\{\left|v_{k j}-v_{i j}\right|\right\} j \in D_{K J}}{\max \left\{\left|v_{k j}-v_{i j}\right|\right\} \forall j}$

c. Menentukan matrik dominan concordance dan discordance

\section{Concordance}

Matrik dominan concordance dapat dibangun dengan bantuan nilai threshold, yaitu dengan membandingkan setiap nilai elemen matriks concordance dengan nilai threshold.

$$
C_{k l} \geq \mathrm{c}
$$

Dengan nilai threshold (c) adalah:

Dewi, Analisis Metode Electre Pada Pemilihan Usaha Kecil Home Industry Yang Tepat Bagi Mahasiswa 


$$
\mathrm{C}=\frac{\sum_{k=1}^{m} \sum_{l=1}^{m} c_{k l}}{m(m-1)}
$$

Sehingga elemen matriks F ditentukan sebagai berikut:

$$
f_{k l}=\left\{\begin{array}{l}
1, j i k a c_{k l} \geq c \\
0, j i k a c_{k l}<c
\end{array}\right\}
$$

\section{Discordance}

Untuk membangun matriks dominan discordance juga menggunakan bantuan nilai threshold (d) yaitu:

$$
\mathrm{D}=\frac{\sum_{k=1}^{m} \sum_{l=1}^{m} d_{k l}}{m(m-1)}
$$

Sehingga elemen matriks $\mathrm{G}$ ditentukan sebagai berikut:

$$
g_{k l}=\left\{\begin{array}{l}
1, j i k a d_{k l} \geq d \\
0, j i k a d_{k l}<d
\end{array}\right\}
$$

d. Menentukan aggregate dominance matriks

Langkah selanjutnya adalah menentukan aggregate dominance matrix sebagai matriks $E$, yang setiap elemennya merupakan perkalian antara elemen matriks $F$ dengan elemen matriks $G$, sebagai berikut :

$$
e_{k l}=f_{k l} \times g_{k l}
$$

e. Eliminasi alternatif yang less favourable

Matriks $E$ memberikan urutan pilihan dari setiap alternatif, yaitu bila $e_{k l}=1$ maka alternatif $A_{k}$ merupakan pilihan yang lebih baik daripada $A_{1}$ Sehingga baris dalam matriks $E$ yang memiliki jumlah $e_{k l}=1$ paling sedikit dapat dieliminasi. Dengan demikian alternatif terbaik adalah yang mendominasi alternatif lainnya

\section{HASIL DAN PEMBAHASAN}

Kriteria yang digunakan dalam pemilihan usaha kecil yang cocok bagi mahasiswa ialah Modal (X1), Keuntungan (X2), Bahan Baku (X3), dan Market (X4). Dalam penelitian ini dipakai data sampel 3 Home industry sebagai alternative untuk melakukan perhitungan manual dengan metode ELECTRE yaitu:

$\mathrm{A}_{1}=$ Olahan Kripik

$\mathrm{A}_{2}=$ Olahan Kue Basah

$\mathrm{A}_{3}=$ Olahan Gorengan

Sebagai tingkatan bobot referensi juga dinilai antara 0 sampai 1, yaitu:
$0.9=$ Sangat Baik
$0.75=$ Setuju
$0.5=$ Cukup
$0.25=$ Tidak Setuju

Tabel 1 Menentukan Rating Kecocokan Pada Setiap Alternatif

\begin{tabular}{ccccc}
\hline & X1 & X2 & X3 & X4 \\
\hline A1 & 0.7571 & 0.7536 & 0.7964 & 0.7571 \\
A2 & 0.7750 & 0.7000 & 0.7458 & 0.7875 \\
A3 & 0.7429 & 0.7750 & 0.7750 & 0.8071 \\
\hline
\end{tabular}


Pada table diatas menunujukan adanya rating yang cocok dari setiap alternative pada setiap kriteria. Karena setiap nilai yang diberikan pada setiap alternatif pada setiap kriteria merupakan nilai kecocokan dimana nilai terbesar adalah nilai terbaik, maka semua kriteria yang diberikan di asumsikan sebagai kriteria keuntungan. $\mathrm{W}=\{0.8,0.8,0.9,0.7$,

Langkah-langkah selanjutnya yang harus dilakukan adalah:

a. Normalisasi Matriks Keputusan

$$
\begin{aligned}
r_{11} & =\frac{x_{11}}{\sqrt{x_{11^{2}}+x_{21^{2}}+x_{31^{2}}}} \\
r_{11} & =\frac{0.7571}{\sqrt{0,7571^{2}+0,7750^{2}+0,7429^{2}}} \\
r_{11} & =\frac{0,7571}{\sqrt{0,5732+0,6006+0,5519}} \\
r_{11} & =\frac{0,7571}{1,7257} \\
r_{11} & =0.5612
\end{aligned}
$$

Tabel 2 Hasil Normalisasi Matriks Keputusan

\begin{tabular}{llll}
\hline 0.5612 & 0.5644 & 0.5515 & 0.5901 \\
\hline 0.5745 & 0.5243 & 0.5165 & 0.6138 \\
0.5506 & 0.5804 & 0.5367 & 0.6291 \\
\hline
\end{tabular}

Pada table diatas merupakan hasil dari normalisasi matriks keputusan.

b. Pembobotan pada matriks yang telah dinormalisasi.

$$
\begin{aligned}
& \mathrm{V}_{11}=\mathrm{W}_{1} \mathrm{R}_{11} \\
& \mathrm{~V}_{11}=0.8 * 0.5612 \\
& \mathrm{~V}_{11}=0.4490
\end{aligned}
$$

Hasil perkalian bobot referensi setiap kriteria dengan matriks keputusan yang telah dinormalisasikan dapat dilihat pada tabel berikut.

\section{Tabel 3 Pembobotan Pada Matriks Yang Telah Dinormalisasi}

\begin{tabular}{llll}
\hline 0.4490 & 0.4515 & 0.4963 & 0.4131 \\
\hline 0.4596 & 0.4194 & 0.4648 & 0.4296 \\
0.4405 & 0.4643 & 0.4830 & 0.4404 \\
\hline
\end{tabular}

c. Menentukan himpunan concordance dan discordance index.

1) Concordance

Sebuah kriteria dalam sebuah alternatif termasuk concordance jika:

$C_{\mathrm{kl}}=\left\{j, y_{k j} \geq y_{l j}\right\}$, untuk $j=1,2,3, \ldots, n$

Hasil concordance yang didapat, yaitu:

$\mathrm{C}_{12}=\{2.3\}$

$\mathrm{C}_{13}=\{1.3\}$

$\mathrm{C}_{21}=\{1.4\}$

$\mathrm{C}_{23}=\{1\}$

$\mathrm{C}_{31}=\{2.4\}$

$\mathrm{C}_{32}=\{2.3 .4\}$ 
Menghitung matriks concordance:

$$
\begin{aligned}
\mathrm{C}_{12} & =\mathrm{W}_{2}+\mathrm{W}_{3} \\
& =0.8+0.9 \\
& =1.7
\end{aligned}
$$

Tabel 4 Hasil Concordance

\begin{tabular}{ccc}
\hline- & 1.7000 & 1.7000 \\
\hline 1.5000 & - & 0.8000 \\
1.5000 & 2.4000 & - \\
\hline
\end{tabular}

2) Discondance

Sebuah kriteria dalam sebuah alternatif termasuk discondance jika:

$D_{\mathrm{kl}}=\left\{j, y_{k j<} y_{l j}\right\}$, untuk $j=1,2,3, \ldots, n$

Hasil discondance yang didapat, yaitu:

$$
\begin{aligned}
& \mathrm{D}_{12}=\{1.4\} \\
& \mathrm{D}_{13}=\{2.3\} \\
& \mathrm{D}_{21}=\{2.3\} \\
& \mathrm{D}_{23}=\{2.3 .4\} \\
& \mathrm{D}_{31}=\{2.4\} \\
& \mathrm{D}_{32}=\{1\}
\end{aligned}
$$

Menghitung matriks descondance :

$$
\begin{aligned}
d_{k l} & =\frac{\max \{|0.4490-0.4596| ;|0.4131-0.4296|\}}{\max \{|| 0.4490-0.4596|;| 0.4515-0.4194|;| 0.4963-0.4648|;| 0.4131-0.4296||\}} \\
d_{k l} & =0.5160
\end{aligned}
$$

Tabel 5 Hasil Discordance

\begin{tabular}{lll}
\hline- & 0.5160 & 1.0000 \\
\hline 1.0000 & - & 1.0000 \\
0.4896 & 0.4242 & - \\
\hline
\end{tabular}

d. Menghitung matriks dominan concordance dqan discordance

1) Menghitung matriks concordance

Nilai threshold (c) adalah:

$\mathrm{C}=\underline{1,7000+1,7000+1,5000+0,8000+1,5000+2,4000}$

$\mathrm{C}=1.6000$

$$
3(3-1)
$$

Sehingga elemen matriks ditentukan sebagai berikut :

$F_{k l}=1$, jika $c_{k l} \geq \mathrm{c}$ dan $f_{k l}=0$, jika $c_{k l}<\mathrm{c}$

Sehingga elemen dominan concordance adalah :

Tabel 6 Matriks Dominan Concordance

\begin{tabular}{ccc}
\hline- & 1 & 1 \\
\hline 0 & - & 0 \\
0 & 1 & - \\
\hline
\end{tabular}

2) Menghitung matriks discordance

Nilai threshold (d) adalah:

$\mathrm{d}=\underline{0,5160+1,0000+1,0000+1,0000+0,4896+0,4242}$

$\mathrm{d}=0.7383$

$$
3(3-1)
$$

Dewi, Analisis Metode Electre Pada Pemilihan Usaha Kecil Home Industry Yang Tepat Bagi Mahasiswa 
Sehingga elemen matriks ditentukan sebagai berikut :

$g_{k l}=0$, jika $c_{k l} \geq \underline{\mathrm{d}}$ dan $g_{k l}=1$, jika $c_{k l}>\underline{\mathrm{d}}$

Sehingga elemen dominan discordance adalah :

Tabel 7 Matriks Dominan Discordance

\begin{tabular}{ccc}
\hline & 0 & 1 \\
\hline 1 & & 1 \\
0 & 0 & \\
\hline
\end{tabular}

e. Menentukan aggregate dominance matrix

Rumus umum untuk anggota matriks aggregate dominance adalah

$\mathrm{E}_{\mathrm{kl}}=\mathrm{f}_{\mathrm{kl}} \times \mathrm{g}_{\mathrm{kl}}$

Sehingga matriks aggregate dominance jika ditampilkan dalam tabel adalah sebagai berikut ini

Tabel 8 Matriks Aggregate Dominance

\begin{tabular}{lll} 
& 0 & 1 \\
\hline 0 & & 0 \\
0 & 0 & \\
\hline
\end{tabular}

Berdasarkan tabel 8 dapat dijelaskan bahwa metode ELECTRE dapat diterapkan dalam pemilihan usaha kecil Home industry yang tepat bagi mahasiswa dengan hasil Olahan Keripik $\left(\mathrm{A}_{1}\right)$ sebagai alternatif terbaik.

\section{PENUTUP}

Berdasarkan penelitian yang dilakukan penulis maka dapat disimpulkan bahwa metode ELECTRE dapat diterapkan dalam pemilihan usaha kecil Home industry yang tepat bagi mahasiswa. Kriteria yang digunakan sebagai penilaian ada 4 kriteria seperti: Modal (X1), Keuntungan (X2), Bahan Baku (X3), dan Market (X4). Alternatif yang menjadi fokus penelitian adalah $\mathrm{A}_{1}=$ Olahan Kripik, $\mathrm{A}_{2}=$ Olahan Kue Basah, dan $\mathrm{A}_{3}=$ Olahan Gorengan. Hasil analisa metode ELECTRE menyebutkan bahwa Olahan Keripik $\left(\mathrm{A}_{1}\right)$ menjadi Home industry yang tepat bagi mahasiswa.

\section{REFERENSI}

[1] D. M. Masyarakat, "Strategi keberhasilan usaha home industry dalam memberdayakan masyarakat," 2017.

[2] S. Hajar, P. Studi, E. Pembangunan, F. Ekonomi, U. T. Umar, and A. Barat, "Analisis Pendapatan Usaha Home Industri,” 2015.

[3] N. A. Hasibuan et al., "Implementasi Data Mining Untuk Pengaturan Layout," vol. 4, no. 4, pp. 6-11, 2017.

[4] A. P. Windarto, L. S. Dewi, and D. Hartama, "Implementation of Artificial Intelligence in Predicting the Value of Indonesian Oil and Gas Exports With BP Algorithm," Int. J. Recent Trends Eng. Res., vol. 3, no. 10, pp. 1-12, 2017.

[5] A. P. Windarto, S. Tinggi, I. Komputer, and T. Bangsa, "Implementation of Data Mining on Rice Imports by Major Country of Origin Implementation of Data Mining on Rice Imports by Major Country of Origin Using Algorithm Using K-Means Clustering Method," no. November, 2017.

[6] S. R. Ningsih and A. P. Windarto, "Penerapan Metode Promethee II Pada Dosen Penerima Hibah P2M Internal," InfoTekJar (Jurnal Nas. Inform. dan Teknol. Jaringan), vol. 3, no. 1, pp. 20-25, 2018.

[7] T. Imandasari, A. Wanto, and A. P. Windarto, "Analisis Pengambilan Keputusan Dalam Menentukan Mahasiswa PKL Menggunakan Metode PROMETHEE," J. Ris. Komput., vol. 5, no. 3, pp. 234-239, 2018. 
[8] P. P. P. A. N. W. F. I. R. H. Zer and A. P. Windarto, "Analisis Pemilihan Rekomendasi Produk Terbaik Prudential Berdasarkan Jenis Asuransi Jiwa Berjangka Untuk Kecelakaan Menggunakan Metode Analytic Hierarchy Process ( Ahp )," CESS (Journal Comput. Eng. Syst. Sci., vol. 3, no. 1, pp. 78-82, 2018.

[9] T. Imandasari and A. P. Windarto, "Sistem Pendukung Keputusan dalam Merekomendasikan Unit Terbaik di PDAM Tirta Lihou Menggunakan Metode Promethee," J. Teknol. dan Sist. Komput., vol. 5, no. 4, p. 159, 2017.

[10] A. Putrama and A. P. Windarto, "Analisis dalam menentukan produk bri syariah terbaik berdasarkan dana pihak ketiga menggunakan ahp," CESS (Journal Comput. Eng. Syst. Sci., vol. 3, no. 1, pp. 60-64, 2018.

[11] A. P. Windarto, "Penilaian Prestasi Kerja Karyawan PTPN III Pematangsiantar Dengan Metode Simple Additive Weighting (SAW)," J. Ris. Sist. Inf. Dan Tek. Inform., vol. 2, no. ISSN 2527 5771, pp. 84-95, 2017.

[12] A. P. Windarto, "Implementation of Data Mining on Rice Imports by Major Country of Origin Using Algorithm Using K-Means Clustering Method," Int. J. Artif. Intell. Res., vol. 1, no. 2, pp. 26-33, 2017.

[13] A. Wanto and E. Kurniawan, "Seleksi Penerimaan Asisten Laboratorium Menggunakan Algoritma AHP Pada AMIK-STIKOM Tunas Bangsa Pematangsiantar," J. Inform. dan Komput., vol. 3, no. 1, pp. 11-18, 2018.

[14] A. H. Aji, M. T. Furqon, and A. W. Widodo, "Sistem Pakar Diagnosa Penyakit Ibu Hamil Menggunakan Metode Certainty Factor (CF)," J. Pengemb. Teknol. Inf. dan Ilmu Komput., vol. 2, no. 5, pp. 2127-2134, 2017.

[15] M. Turnip, "Sistem Pakar Diagnosa Penyakit THT Menggunakan Metode Backward Chaining," no. January 2015, 2017.

[16] A. P. Windarto, M. R. Lubis, and Solikhun, "Implementasi Jst Pada Prediksi Total Laba Rugi Komprehensif Bank Umum Konvensional Dengan Backpropagation," J. Teknol. Inf. dan Ilmu Komput., vol. 5, no. 4, pp. 411-418, 2018.

[17] A. P. Windarto, M. R. Lubis, and Solikhun, "Model Arsitektur Neural Network Dengan Backpropogation Pada Prediksi Total Laba Rugi Komprehensif Bank Umum Konvensional," Kumpul. J. Ilmu Komput., vol. 5, no. 2, pp. 147-158, 2018.

[18] T. Budiharjo, Soemartono, T., Windarto, A.P., Herawan, "Predicting school participation in indonesia using back-propagation algorithm model," Int. J. Control Autom., 2018.

[19] T. Budiharjo, Soemartono, T., Windarto, A.P., Herawan, "Predicting tuition fee payment problem using backpropagation neural network model," Int. J. Adv. Sci. Technol., 2018.

[20] I. Tri, R. Yanto, M. Akmar, and T. Herawan, "Engineering Applications of Arti fi cial Intelligence A modi fi ed Fuzzy k -Partition based on indiscernibility relation for categorical data clustering," vol. 53, pp. 41-52, 2016.

[21] T. Takagi and M. Sugeno, "Fuzzy Identification of Systems and Its Applications to Modeling and Control," IEEE Trans. Syst. Man Cybern., vol. SMC-15, no. 1, pp. 116-132, 1985.

[22] N. Butarbutar, A. P. Windarto, D. Hartama, and S. Solikhun, "Komparasi Kinerja Algoritma Fuzzy C-Means Dan K-Means Dalam Pengelompokan Data Siswa Berdasarkan Prestasi Nilai Akademik Siswa," Jurasik (Jurnal Ris. Sist. Inf. dan Tek. Inform., vol. 1, no. 1, p. 46, 2018.

[23] M. G. Sadewo, A. P. Windarto, and D. Hartama, "Penerapan Datamining Pada Populasi Daging Ayam Ras Pedaging Di Indonesia Berdasarkan Provinsi Menggunakan K-Means Clustering," InfoTekJar (Jurnal Nas. Inform. dan Teknol. Jaringan), vol. 2, no. 1, pp. 60-67, 2017.

[24] B. Supriyadi, A. P. Windarto, T. Soemartono, and Mungad, "Classification of natural disaster prone areas in Indonesia using K-means," Int. J. Grid Distrib. Comput., vol. 11, no. 8, pp. 8798, 2018. 
[25] A. P. Windarto, P. Studi, S. Informasi, and D. Mining, "Penerapan Data Mining Pada Ekspor Buah-Buahan Menurut Negara Tujuan Menggunakan K-Means Clustering," vol. 16, no. 4, pp. 348-357, 2017.

[26] Sudirman, A. P. Windarto, and A. Wanto, "Data mining tools | rapidminer: K-means method on clustering of rice crops by province as efforts to stabilize food crops in Indonesia," IOP Conf. Ser. Mater. Sci. Eng., vol. 420, p. 12089, 2018.

[27] K. Fatmawati and A. P. Windarto, "Data Mining: Penerapan Rapidminer Dengan K-Means Cluster Pada Daerah Terjangkit Demam Berdarah Dengue (Dbd) Berdasarkan Provinsi," Comput. Eng. Sci. Syst. J., vol. 3, no. 2, p. 173, 2018.

[28] D. M. Sinaga, S. M. Dewi, and A. P. Windarto, "Penerapan Algoritma ELECTRE Pada Pemilihan Produk Skincare," vol. 13, no. 2, 2018.

[29] R. W. Sari, A. P. Windarto, S. P. Keputusan, P. Kreatifitas, M. Pkm, and A. D. A. N. Pembahasan, "Penerapan Electree Pada Seleksi Proposal Program Kreativitas Mahasiswa ( PKM ) di STIKOM Tunas Bangsa," pp. 800-806, 2019.

[30] F. Setiawan, F. Indriani, and Muliadi, "Implementasi Metode Electre Pada Sistem Pendukung Keputusan SNMPTN Jalur Undangan,” Kumpul. J. Ilmu Komput., vol. 2, no. 2, pp. 88-101, 2015.

[31] S. T. Bangsa, "Sistem Pendukung Keputusan Dengan Menggunakan Metode Electre Dalam Merekomendasikan Dosen Berprestasi Bidang Ilmu Komputer ( Study Kasus di Sistem Pendukung Keputusan Dengan Menggunakan Metode Electre Dalam Merekomendasikan Dosen Berprestasi Bidang Ilmu K," no. September, 2017. 